\title{
Los principios teóricos de Cutter, Kaiser y Ranganathan como elementos de interlocución en organización del conocimiento
}

\author{
Princípios teóricos de Cutter, Kaiser e Ranganathan \\ como elementos de interlocução na Organização do Conhecimento
}

Theorical principles of Cutter, Kaiser and Ranganathan

as elements of dialogue in knowledge organization

\begin{abstract}
Rodrigo de SALES (1), José Augusto Chaves GuimARÃES (2)
Faculdade de Filosofia e Ciências - UNESP, - Av. Hygino Muzzi Filho, 737 Marília - São Paulo - Brasil - CEP: 17525-900.
\end{abstract}

(1) rodrigo.sales.s@gmail.com. (2) guima@marilia.unesp.br

\begin{abstract}
Resumo
El universo de investigación de la organización del conocimiento requiere consistencia en su concepción teórica para que su aplicación práctica se desarrolle de forma efectiva y satisfactoria. En esta dirección, se aborda la relación de interlocución entre los principios teóricos definidos por Cutter en la catalogación temática, por Kaiser en la indización sistemática y por Ranganathan en la clasificación facetada. Se concluye que estos tres teóricos bibliotecarios situaron en diferentes momentos de la evolución de la disciplina a las facetas en el centro teórico de la organización del conocimiento.
\end{abstract}

Palabras clave: Cutter. Kaiser. Ranganathan. Organización del Conocimiento. Tratamiento temático de la información. Clasificación facetada.

\section{Introdução}

A organização do conhecimento, enquanto área de estudo, consiste em um espaço investigativo que envolve o contexto dos saberes e fazeres profissionais inerentes à Ciência da Informação. Esse espaço de investigação possui caráter mediador na medida em que torna factível a dialogicidade entre os contextos de produção e de uso da informação (1).

No âmbito da organização do conhecimento, observa-se duas dimensões relativas ao tratamento da informação - a dimensão descritiva (relativa à forma dos documentos) e a dimensão temática (voltada aos conteúdos informacionais). A segunda dimensão, como disse Foskett (1973), vem sendo representada por meio do termo Tratamento Temático da Informação (Subject Approach to Information) que, segundo o próprio autor, é um fazer de natureza media-

\begin{abstract}
The research universe of knowledge organization requires a consistent theoretical conception that promotes an effective application of its tools. In this sense, a dialogical basis is established among the theoretical principles of Cutter's Subject Cataloguing, Kaiser's Systematic Indexing and Ranganathan's Faceted Classification, as a basis for a theoretical timeline of the epistemology of knowledge organization. It is possible to conclude that those three theoretical approaches can be organized in a chronological and conceptual row, showing the growing importance of facets in knowledge organization theory.
\end{abstract}

Keywords: Cutter. Kaiser. Ranganathan. Knowledge Organization. Subject Approach to Information. Faceted Classification.

dora voltado para o acesso ao conteúdo informacional. Segundo Barité (1998, p. 124), o Tratamento Temático da Informação (TTI) centra-se nas questões relativas "à análise, descrição e representação do conteúdo dos documentos, bem como suas inevitáveis interfaces com as teorias e sistemas de armazenamento e recuperação da informação" em cujo âmbito desenvolvem-se processos, instrumentos e produtos.

Teoricamente, o tratamento temático desenvolveu-se sob três abordagens: a subject cataloguing de matriz norte-americana (final do século $X I X$ ), a indexing de matriz inglesa (meados do século $X X)$ e a analyse documentaire de matriz francesa (década de 1960). Embora essas três vertentes teóricas se diferenciem quanto à ênfase dada aos seus fazeres - catalogação de assunto focada no desenvolvimento de produtos, indexação focada no desenvolvimento de instrumentos e análise documental focada no desenvolvimento de referenciais teórico- 
metodológicos para os procedimentos envolvidos no TTI (Guimarães, 2008 e 2009) - elas constroem juntas o arcabouço teórico do tratamento temático da informação.

É notadamente nos contextos da catalogação de assunto e da indexação que o universo da organização do conhecimento, particularmente do tratamento temático, começou a investir esforços em direção a uma sistematização do fazer profissional da área, que por sua vez, geraram princípios teóricos fundamentais, tais como os encontrados na Classificação Facetada.

A vista de tais aspectos, apresenta-se aqui, uma articulação entre princípios teóricos encontrados no Dictionary Catalog de Cutter (catalogação de assuntos), na Systematic Indexing de Kaiser (indexação de assuntos) e na Colon Classification de Ranganathan (classificação de assuntos) que indicam uma interlocução formadora do pensamento relativo à organização do conhecimento com base em facetas, mostrando que, embora consolidada por Ranganathan, a teoria da classificação facetada começou a ser teoricamente delineada a partir de Cutter e Kaiser. Tal fato, sugere ao universo da organização do conhecimento a concepção de uma linha conceitual evolutiva composta pelas catalogação, indexação e classificação de assuntos.

\section{O Dictionary Catalog de Cutter: princípios da catalogação de assunto}

A grande contribuição do bibliotecário norteamericano Charles Ammi Cutter (1837-1903) para o tratamento temático da informação encontra-se na obra Rules for a Dictionary Catalog (1876), que se situa na abordagem da Catalogação de Assunto. A catalogação de assunto enquanto abordagem teórica reflete uma tradição pragmática anglo-saxônica centrada na geração de produtos advindos do TTI em bibliotecas. Fundamentalmente de matriz norteamericana, tem seus princípios fundados na catalogação alfabética de Cutter e nos cabeçalhos de assunto desenvolvido pela Library of Congress (Guimarães, 2009). As regras para um catálogo dicionário de Cutter definem princípios que o levou à grande notoriedade no campo da Biblioteconomia (Barbosa, 1969; Foskett, 1973; Maltby, 1975; Piedade, 1977 e Coates, 1988). A referida obra de Cutter recebeu esse nome porque "os cabeçalhos (autor, título, assunto e forma) são organizados como as palavras em um dicionário, em ordem alfabética" (Cutter, 1904, p. 19, tradução livre).

As regras para elaboração de catálogos alfabéticos de Cutter foram criadas em um contexto em que, segundo Chaumier (1988), a vertente dos estudos de linguagens documentais se volta para os padrões de consistência de índices e elaboração de esquemas de estrutura alfabético-combinatória. Quando Cutter publicou as Rules for a Dictionary Catalog o universo da catalogação ganhou nova roupagem, passou a ser tratado com maior rigor mediante um verdadeiro tratado de catalogação (Barbosa, 1969 e Piedade, 1977), ou pilar fundamental da catalogação de assunto norteamericana (Foskett, 1973) e, com um caráter pragmático voltado ao usuário (Mey, 1987). Fujita (1989) lembra que as regras estabelecidas por Cutter diziam respeito não somente à construção dos cabeçalhos, mas também de seu arranjo.

Para Cutter (1904), a importância de decidir corretamente a entrada de um assunto, quando da realização da catalogação, se deve ao fato de que se não houver um princípio óbvio para orientar o catalogador não haverá o porquê de o público usuário acreditar que encontrará o que necessita usando um termo de entrada em detrimento de outro. E o maior benefício da existência de tal princípio é, para Cutter (1904), a probabilidade de uma convergência nas decisões tomadas por diferentes catalogadores no momento da elaboração e escolhas dos cabeçalhos.

As regras de Cutter estão divididas em duas grandes partes, a primeira dedicada à Entrada (2) (Onde entrar) e a segunda dedicada ao Estilo (Como entrar). Na primeira parte, onde são detalhados os elementos que podem ou devem ser considerados como fundamentais na formação dos cabeçalhos, Cutter apresenta separadamente, no item subject-catalog, como se deve proceder para: a) a escolha de diferentes assuntos; b) a escolha entre diferentes nomes e; c) a decisão sobre o número (quantidade) de entradas de assunto. Além disso, expõe uma miscelânea de regras e exemplos e disserta sobre as entradas que podem ser consideradas partes de um todo (Cutter, 1904). Têm-se aí, muito provavelmente, o início da relação todoparte adotado posteriormente nos estudos práticos e teóricos das linguagens documentais, particularmente nos tesauros. Na segunda parte o autor apresenta, dentre outros itens, detalhes sobre o arranjamento dos assuntos.

As regras de Cutter para a elaboração dos cabeçalhos eram fundamentadas em três princípios básicos:

1. princípio específico - Os assuntos devem dar entrada pelo termo mais específico e não pela classe a que está subordinada. Apesar de parecer óbvio, este princípio causou impacto porque na época era comum a adoção de cabeçalhos bastan- 
te gerais, que pouco representavam o assunto da obra em questão (Cesarino e Pinto, 1978, p. 274)

2. princípio de uso - Para ele "os cabeçalhos serão aqueles sob os quais é provável que a maioria dos americanos educados irão procurar, com referências cruzadas para outras formas de cabeçalhos relacionados". É o princípio da conveniência, de acordo com a necessidade dos usuários (Cesarino e Pinto, 1978, p. 275)

3. princípio sindético - Por se basearem no alfabeto dos cabeçalhos de assunto fazem aproximações absurdas de assuntos e ao mesmo tempo, separam assuntos relacionados. Assim Cutter propôs o desenvolvimento nas listas de cabeçalhos de assunto de estruturas sindéticas que, através de uma rede bem construída de referências cruzadas, poderiam ajudar ou mesmo superar este problema (Cesarino e Pinto, 1978, p. 275).

Quando Cutter define que os assuntos devem dar entrada pelo termo mais específico e não pela classe a que está subordinada (princípio específico), deve-se ater ao fato de que, como afirma Foskett (1973), Cutter apresentava razões mais econômicas e menos teóricas, motivo pelo qual sua abordagem alfabética não contemplava as remissivas ao tipo descendente - de assuntos gerais para específicos.

Quanto ao princípio de uso, Cutter apresentava uma postura dedutiva, pontuando que o cabeçalho deveria ser escolhido de acordo com a dedução de quais os termos seriam provavelmente relacionados pelo usuário no momento da busca.

O princípio sindético de Cutter, o qual sustenta que há a necessidade de uma rede cruzada de referências entre os cabeçalhos de assuntos, demonstra um pioneirismo fundamental em que pese à questão do 'relacionamento entre assuntos'. Verifica-se assim que Cutter fincou pilares iniciais para a futura aparição da classificação facetada, tornando-se, portanto, um dos precursores da representação do conhecimento baseada em princípios voltados ao relacionamento entre assuntos.

\section{O Systematic Indexing de Kaiser: princípios da Indexação de assuntos}

O bibliotecário alemão Julius Otto Kaiser (19681927) tem seu nome gravado nos escritos oriundos da classificação e indexação devido à publicação da obra Systematic Indexing (1911). Com a referida obra, onde o autor apresenta uma maneira sistemática para a realização do processo de indexação de assuntos de documentos, o universo do tratamento da informação, até então familiarizado com a classificação e com a catalogação alfabética de assun- tos, direciona também a atenção para a indexação alfabética de assuntos, prática esta que foi revigorada com o sistema de Kaiser.

Atento às coleções de conteúdos heterogêneos, Kaiser, de certa forma, deu continuidade aos estudos de Cutter no que se refere à catalogação de assunto (Coates, 1988; Rodriguez, 1984). Assim como Cutter procurou resolver o problema da inconsistência na catalogação de assuntos, definindo regras para a elaboração de cabeçalhos de assuntos, Kaiser elaborou uma forma sistemática, também permeada por regras, para a construção de sentenças terminológicas que melhor representassem o assunto de um livro. O que na época de Cutter era denominado cabeçalhos de assuntos (subject headings), Kaiser chamou de enunciado (statement). O enunciado, a exemplo do cabeçalho de assunto, nada mais era do que uma palavra ou grupo de palavras que expressavam o conteúdo de um documento. Porém, o avanço de Kaiser reside notadamente nos elementos que compõem tal enunciado.

Com o intuito de alcançar o objetivo principal do systematc indexing - "descobrir aqueles elementos por meio dos quais poderemos trazer conhecimento ou informação de algum tipo" (Kaiser, 1911 citado por Rodriguez, 1984, p. 165 , tradução livre) - o que evidencia a intenção de extrair de um livro os termos que melhor representassem seu assunto - Kaiser estabeleceu categorias que nortearam seu sistema. Partindo do pensamento de que "no mundo existem coisas e que essas coisas podem ser ditas ou descritas" (Rodriguez, 1984, p. 164), Kaiser preconizou que todos os assuntos podem ser mais bem representados e descritos por meio de duas categorias fundamentais: Concretos e Processos.

Kaiser simplificou a prática de indexação sintetizando o cabeçalho (enunciado) em terms commodities (nomes) e terms of action (verbos). $\mathrm{O}$ assunto propriamente dito, ou seja, a coisa da qual um livro trata é o Concreto, ao passo que o que é dito a respeito dessa coisa (concreto) é o Processo.

\section{Segundo Kaiser (1911, pr. 73),}

para fins de indexação devemos dividir nosso estoque de nomes ou termos entre concretos, processos e países, sendo os concretos os produtos com os quais estamos interessados, processos indicando suas ações, e os países indicando as localidades com as quais os concretos estão conectados (Tradução livre - grifo nosso).

A importância das duas categorias fundamentais, concreto e processo, é explicada pelo próprio Kaiser por meio da afirmação de que 
"concretos são conhecidos por nós apenas superficialmente [...] somos incapazes de dar uma completa descrição a qualquer concreto" (Kaiser, 1911, pr. 54, tradução livre). E segue, "não podemos dizer o que são os concretos, somos obrigados a dar maior atenção aos seus processos, para o que eles fazem ou o que podemos fazer com eles" (pr. 55, tradução livre).

Para Maltby (1975), concretos são entidades e processos são operações. Coates (1988) e lyer (1995) convergem ao afirmarem que concretos são coisas, lugares e termos abstratos que não significam ações. Para os autores, processos podem significar: "a) modo de tratamento do assunto pelo escritor; b) uma ação ou processo descrito em um documento; ou c) um adjetivo relativo ao concreto como complemento para 0 assunto" (tradução livre).

O enunciado de Kaiser é formado primeiramente pelo concreto (termo de entrada) e em seguida pelo processo. O concreto pode estar presente no enunciado sem a presença do processo, mas o contrário não se aplica, para existir um processo é necessária a presença de um concreto. Assim, o enunciado de um documento que trata de editoração de periódicos seria: Periódicos - Editoração.

Para o systematic indexing um termo que denota processo em um dado enunciado pode assumir a função de concreto em outro enunciado, dependendo sempre do assunto do documento que está sendo tratado.

Preocupado também com o nível de especificidade dos enunciados, Kaiser contemplou em seu sistema a possibilidade de ampliações do enunciado com a intenção de proporcionar maior informação a respeito do documento que está sendo indexado. Tal ampliação permite a inserção de mais um termo processo no enunciado.

Com relação à categoria localidades, Foskett (1973) e Coates (1988) explicam que caso esteja incluído um lugar no assunto do documento, o sistema de Kaiser define que seja feita uma entrada dupla, ou seja, um enunciado a partir do concreto e outro a partir da localidade. Essa ultima é realizada de maneira indireta, sempre pelo país seguido pela subdivisão de local (cidade). Assim, editoração de periódicos na cidade de Zaragoza, o enunciado seria:

Periódicos - Espanha, Zaragoza - Editoração e Espanha. Zaragoza - Periódicos - Editoração

Além de estabelecer categorias, Kaiser, a exemplo de Cutter, definiu regras para a formação dos enunciados. São seis as regras estabelecidas com o objetivo de obter êxito no processo de indexação. A saber (Kaiser, 1911, pr. 348, tradução livre):

1) Selecione o que é realmente importante para seu objetivo sem considerar forma ou extensão;

2) Concentre-se na informação relativamente específica;

3) Lide com cada item independentemente;

4) Não adultere o nome dos concretos;

5) Evite inversão, preposições e plurais sempre que possível;

6) Teste a exatidão de cada enunciado pelo ponto de vista tanto do indexador quanto do usuário.

Observa-se que Kaiser se assemelha a Cutter não somente na iniciativa de estabelecer regras para a formação de termos de indexação, mas notadamente nos focos abordados. O princípio específico de Cutter encontra-se também nas regras de formação dos enunciados. Enquanto Cutter definia que os assuntos devem dar entrada pelo termo mais específico e não pela classe a que está subordinada, Kaiser estabelecia que o foco devesse ser a informação relativamente específica. Embora ambos tenham se preocupado com a questão da especificidade do termo de representação de assuntos, Kaiser avançou a questão prevendo a necessidade que havia de possibilitar referências de assuntos específicos para os assuntos gerais, inexistente no catálogo dicionário de Cutter (Foskett, 1986). Segundo Foskett (1973), a ligação dos concretos em redes de remissivas coordenadas de forma superordenada e subordinada, prevista no sistema de Kaiser, é o mais adequado.

Mills (1960) explica que os termos eram relacionados na rede de remissivas de Kaiser por meio de cartões guias que especificavam, além das relações de termos superordenados e subordinados, também termos sinônimos e qualquer outro termo/concreto que apresentasse alguma conexão encontrada no momento da indexação da coleção. Nota-se que essas relações entre termos tecidas no systematic indexing é uma continuidade do princípio sindético preconizado por Cutter.

Essa atenção dada aos tipos de relacionamento entre os termos, iniciada no catálogo dicionário de Cutter por meio das referências cruzadas e avançadas no sistema de Kaiser por meio das redes de remissivas, é o início de uma preocupação que permeia os estudos de classificação desenvolvidos posteriormente por Ranganathan.

Kaiser volta-se também à preocupação apresentada no princípio de uso de Cutter. Ambos os sistemas estão voltados não apenas para o êxito da representação (catalogação e inde- 
xação), mas principalmente para a satisfação das necessidades dos usuários. E nesse ponto, mais uma vez é possível verificar um avanço de Kaiser com relação ao trabalho iniciado por Cutter. Enquanto este apresentava uma postura mais dedutiva, pontuando que o cabeçalho deveria ser escolhido de acordo com a dedução de quais os termos seriam provavelmente relacionados pelo usuário, aquele buscava extrair do próprio usuário a exatidão dos enunciados.

O sistema baseado em categorias de Kaiser era suficiente dentro de certos limites e insuficiente para lidar com a bibliografia moderna (Foskett, 1973), haja vista que sua concepção muito prática e simplista não contemplava maiores regras para situações específicas (Turner apud Straioto E Guimarães, 2004). Porém, Kaiser se aproximou mais da solução de problemas básicos da indexação do que qualquer outro antes (Metcalfe, 1959), como por exemplo, a solução do problema na ordem de importância (Foskett, 1973). Conseguiu contemplar as dimensões estáticas (concretos) e dinâmicas (processos) do conteúdo de um documento (Straioto E Guimarães, 2004) e, sobretudo, lançou os princípios de facetagem (Cesarino e Pinto, 1978; Rodríguez, 1984; Straioto e Guimarães, 2004).

As idéias de Kaiser são estudadas tanto pelo universo investigativo da classificação quanto da indexação, fato que torna possível afirmar que ele foi um elo entre as classificações filosóficas e bibliográficas, que são sistemas nos quais prevalecem as visões e as lógicas dos criadores dos sistemas, com a indexação de assuntos, onde o que impera são as visões dos utilizadores do sistema. Lançando mão de princípios de Classificação, Kaiser concebeu uma nova forma de indexar.

\section{A Colon Classification de Ranganathan: consolidação da classificação facetada}

Em 1933 o bibliotecário e matemático indiano Shiyali Ramamrita Ranganathan (1892-1972), publicou a primeira edição da Colon Classification (CC), ou Classificação dos Dois Pontos (CD), que ganhou esse nome pelo fato de os assuntos serem relacionados em um primeiro momento pelo sinal gráfico 'dois pontos' (:).

O sistema de Ranganathan não surgiu para o universo da organização e representação do conhecimento simplesmente como uma nova classificação, a classificação com base em facetas de assuntos definida por Ranganathan transcende o papel das classificações lineares e rigorosamente hierárquicas existentes até então, configurando um novo modo de classifi- car assuntos. Algo semelhante, porém nem tão repercutido, ocorreu, como já mostrado anteriormente, com Cutter - que criou um novo modo de formar cabeçalhos - e com Kaiser - que criou um novo modo de indexar assuntos. Portanto, a transformação ocorrida no universo das classificações diante da publicação da Colon Classification é o efeito não do surgimento de uma nova classificação, mas sim da emersão de um novo método, que obteve um total de sete edições (1933, 1939, 1950, 1952, 1957, 1960 e 1987) contidas de significativas modificações e inúmeras reimpressões (Mills, 1960; Barbosa, 1969; Foskett, 1973; Maltby, 1975; Langridge, 1977; Piedade, 1977 e 1983; Coates, 1988 e Straioto \& Guimarães, 2004).

Embora Dewey já tenha antes incluído alguns elementos de síntese em suas notações decimais, e Otlet e La Fontaine já tivessem lançado mão de um conjunto semiótico nas notações da CDU, Ranganathan foi quem fortaleceu o desenvolvimento de um sistema puramente analítico-sintético, pois, como informa Foskett (1973), ele conseguiu demonstrar que análise e síntese podem ser aplicadas a qualquer classe de assunto, e assim ser sistematizadas. Ademais, Ranganathan desenvolveu sob um rigor científico uma terminologia própria utilizada até hoje para os estudos de classificação. Termos como facetas (facets), focos (focus ou foci), ciclos (rounds), níveis (levels), coordenação e subordinação de assuntos (arrays and chains) foram incorporados no universo investigativo das classificações a partir de Ranganathan.

A Classificação dos Dois Pontos era baseada no agrupamento de assuntos que apresentavam as mesmas características e os mesmos tipos de relacionamentos, e as subdivisões do conhecimento podiam se originar por meio de diversas relações, entre elas, gênero-espécie, todo-parte, propriedade-possuidor, ação-paciente ou agente etc.

O entendimento aprofundado da lógica da Classificação dos Dois Pontos é possível por meio dos livros publicados pelo próprio Ranganathan. Como consta na Introdução (Capítulo 00) da quarta reimpressão da sexta edição da Colon Classification

A proposta deste livro não é expor a filosofia de classificação, ou discutir suas teorias, ou fornecer um livro de práticas, uma cartilha. Essas propostas são fornecidas pelo autor em 1) Philosophy of Library Classification; 2) Classification and Communication 3) Prolegomena to Library Classification, referenciado posteriormente como Prolegonema; 4) Library Classification: fundamentals and procedures; 5) Elements of Library Classification, referenciado posteriormente como Elements [...] A 
proposta do presente livro é fornecer os esquemas da Classificação dos Dois Pontos, e as regras para construir o número de classificação [Colon Number] para qualquer assunto (Ranganathan, 1976, p. 12. Tradução livre).

A obra de 1976, supracitada, refere-se à quarta reimpressão da sexta edição (de 1960) da CoIon Classification, publicada posteriormente ao falecimento de Ranganathan.

Nota-se, na definição acima, que não era apenas um sistema de classificação que Ranganathan objetivava conceber, mas sim edificar bases teóricas e propiciar de forma sistemática a construção de códigos capazes de classificar qualquer assunto, por meio de regras e esquemas classificatórios.

Para alcançar seu modelo teórico, Ranganathan, tendo de solucionar a insuficiência referente à síntese proporcionada apenas pelos dois pontos, desenvolveu um princípio teórico que reformou completamente seu sistema, o princípio das categorias fundamentais: Personalidade $(P)$, Matéria $(M)$, Energia $(E)$, Espaço $(S)$ e Tempo (T), conhecido como PMEST. Observase a relação das categorias Personalidade, Energia e Espaço respectivamente com as categorias Concreto, Processo e Lugar de Kaiser. Esse princípio zelava pela ordem de citação de concretude decrescente, e passou a ser empregado a partir da quarta edição. Como ressaltam Foskett (1973) e Coates (1988), a análise baseada nas categorias PMEST podem não solucionar por completo a questão da ordem de citação, mas muitas vezes são uteis para o estabelecimento da ordem de citação adequada de assuntos. Além do mais, não há, segundo os autores, registro de esquemas classificatórios que tenham tratado tal questão com tanto empenho e clareza até então. Os mesmos autores afirmam que uma desvantagem da determinação do PMEST é a inflexibilidade, pois não se prevê uma adaptação na ordem de citação para determinado grupo de usuário se tal ordem colidir com o PMEST.

Para Ranganathan (1976) cada faceta de qualquer assunto é considerada como uma manifestação de uma das cinco categorias fundamentais: Personalidade (objeto estudado), Matéria (materiais e substâncias), Energia (ações e processos), Espaço (local) e Tempo (época). Para ele as cinco categorias fundamentais são dadas sob uma seqüência crescente de concretude com os respectivos símbolos de ligação: apóstrofe invertido (') Tempo, ponto (.) Espaço, dois pontos (:) Energia, ponto e vírgula (;) Matéria, vírgula (,) Personalidade (p. 1.25).
A característica principal da Colon Classification é a sua subdivisão em facetas e focos. Segundo Ranganathan, citado por Barbosa (1969, p. $166)$, análise de assunto por facetas significa

que cada aspecto desse assunto pode ser visto como as manifestações de certas características ou facetas que obedecem a postulados prédeterminados. O sistema torna-se assim multidimensional e ilimitado.

Faceta pode ser entendida como um aspecto (característica) particular de um assunto, e cada faceta é dividida por focos ou, como afirma Barbosa (1969), por focos isolados. Para Foskett (1973), um isolado é um termo fora de contexto, que inserido no contexto de uma faceta torna-se um foco dessa faceta. Lima (2004) complementa afirmando que o isolado é uma idéia, ou conjunto de idéias, que serve para formar um assunto, mas para tanto, necessita estar inserido em algum contexto de assunto.

Imagina-se a classe de assunto 'Biblioteconomia' subdividida segundo a característica ou faceta 'Item Bibliográfico' de coleções de bibliotecas (Quadro 1):

\begin{tabular}{ccc}
\hline Classe & Faceta & Focos \\
\hline Biblioteconomia & Item & Livro, Periódico \\
& Bibliográfico & Dicionário, Tese \\
\hline
\end{tabular}

Quadro 1. Faceta e Focos

Os termos Livro, Periódico, Dicionário, Anais e Tese são focos porque estão inseridos no contexto da faceta 'Item Bibliográfico', caso não estivessem contextualizados, os mesmos termos seriam apenas isolados. Ao concentrar a atenção somente em um dos focos, como por exemplo, no termo Livro, pode-se afirmar que na faceta 'Item Bibliográfico' o foco atingido foi 0 Livro.

Ciclos e níveis são outros dois termos empregados por Ranganathan em seu sistema. Como visto anteriormente, cada faceta é a manifestação de uma das cinco categorias PMEST. Porém, uma categoria fundamental pode se manifestar mais de uma vez na mesma classe de assunto por meio de suas facetas, ou combinações de facetas; a essa manifestação recorrente da mesma categoria em uma dada classe de assunto Ranganathan denomina ciclo (Mills, 1960; Barbosa, 1969; Foskett, 1973 e Piedade, 1983). Em um mesmo ciclo também pode ocorrer mais de uma manifestação da mesma categoria fundamental, a essa recorrência Ranganathan denominou níveis.

Ranganathan lançou mão do termo array conceituando-o como um 'conjunto de classes 
coordenadas derivadas de uma mesma característica'. Na subdivisão proporcionada por esse princípio de coordenação era possível a divisão de um grande assunto em classes coordenadas de assuntos menores; a essa subdivisão Ranganathan denominou Dissecação (Dissection), e as classes de assuntos menores (classes subordinadas) fora chamadas de chains (redes ou cadeias). Essas classes subordinadas consistiam, segundo Barbosa (1969, p. 171-2), em "subdivisões de assuntos de grande extensão e pequena intenção em assuntos de pequena extensão e grande intenção" e acarretava na "produção de uma cadeia de assuntos subordinados"; esse tipo de representação é denominada por Ranganathan de Denudação (Denudation) (Barbosa, 1969 e Lima, 2004).

Para proporcionar maior flexibilidade (hospitalidade) ao seu sistema, tanto nas classes coordenadas quanto nas subordinadas, Ranganathan definiu alguns princípios denominados cânones (canons), que são complementados por processos de ampliação da flexibilidade, e estão apresentados no Prolegomena to Library Classification (1937). Para citar alguns: Cânones - Exaustividade, Sequência útil, Sequência exclusiva, Sequência consistente, Extensão decrescente e Modulação; Processos de ampliação - interpolação entre dígitos de notação e criação de novos assuntos.

A exemplo de Cutter e Kaiser que respectivamente se preocuparam em conceber uma nova maneira de catalogar e indexar assuntos, Ranganathan, com sua classificação facetada, alavancou uma nova maneira de classificar assuntos. Indo além da concepção de um sistema classificatório, ele criou uma metodologia para a construção de classificações, propiciando esquemas autoperpetuantes. Sua fundamentação pautada na análise e síntese de facetas e focos, sua preocupação com a ordem de citação e com os relacionamentos coordenados e subordinados, e ainda, seu empenho em proporcionar maior hospitalidade (flexibilidade) com o intuito de permitir a criação de novas facetas, novos focos e novos números de classificação de assuntos, faz de seu trabalho um marco no compromisso de extrair os aspectos mais significativos de assuntos de documentos.

As bases lógicas de Ranganathan amadureceram os princípios de uso, de especificidade, de relacionamento entre assuntos e de estabelecimento de categorias e de regras presentes ora em estudos de Cutter ora em estudos de Kaiser, consolidando uma teoria - a teoria da Classificação Facetada.

\section{Perspectivas dialógicas entre Cutter, Kaiser e Ranganathan}

Cutter, Kaiser e Ranganathan revelam convergências ao investirem em delineamentos de regras para a formação de termos de representação de assuntos - cabeçalhos de assuntos (Cutter), enunciados de assuntos (Kaiser), e notações classificatórias (Ranganathan). As contribuições convergentes e complementares de Cutter para a catalogação, de Kaiser para a indexação, e de Ranganathan para a classificação, evidencia uma construção teórica no universo da organização do conhecimento, particularmente no tratamento temático, que foi amadurecendo no transcorrer da história e propiciou um ambiente favorável à consolidação de uma teoria de classificação facetada. Teoria essa que se sedimentou no âmbito universal (enciclopédico) e penetrou posteriormente nos âmbitos especializados.

No que se refere ao princípio de especificidade, Cutter define que a entrada do cabeçalho deve ser feita pelo termo mais específico (desconsiderando as classes gerais de assunto). Kaiser avança esta questão permitindo a ampliação do enunciado com mais um termo/processo e prevendo a entrada dupla para lugares (quando o lugar for parte do assunto). Em Ranganathan, a questão da especificidade está explicitada nas quatro primeiras leis que regeram seu sistema livros são para serem usados; a cada leitor seu livro; a cada livro seu leitor e; poupe o tempo do leitor (3).

O princípio de uso, abordado pioneiramente por Cutter, também foi preocupação de Kaiser. As regras definidas por ambos voltavam-se não apenas para o êxito da representação (catalogação e indexação), mas principalmente para a satisfação das necessidades dos usuários. E nesse ponto, mais uma vez se verifica um avanço de Kaiser com relação ao Cutter, pois enquanto este apresentava uma postura mais dedutiva (o cabeçalho deveria ser escolhido de acordo com a dedução de quais os termos seriam provavelmente relacionados pelo usuário), aquele buscava na avaliação do próprio usuário a adequação dos enunciados. A questão do uso tanto por parte do utilizador do sistema quanto por parte do usuário da biblioteca também foi preocupação de Ranganathan. Porém, há que se ressaltar a flexibilidade parcial do sistema de Ranganathan nesse quesito (aliás, essa flexibilidade limitada também é encontrada no caráter dedutivo de Cutter e na insuficiência das categorias de Kaiser). Ao mesmo tempo em que a classificação e os livros de Ranganathan instrumentalizavam o classificador de tal modo que 
Ihe proporcionava a habilidade de criar novos assuntos e relacionamentos entre assuntos (por meio da criação de novas facetas e focos), eles predeterminavam, como afirma Lima (2004), listas exaustivas de possíveis categorias e organizavam as facetas em uma única ordem prescritiva, independente do assunto.

É no princípio do relacionamento entre os termos que se observa um exponencial avanço no sistema facetado de Ranganathan. As referências cruzadas de assuntos correlatos (do princípio sindético de Cutter) e as redes de remissivas entre termos superordenados, subordinados e sinônimos (da indexação sistemática de Kaiser) são potencializadas significativamente na classificação de Ranganathan. As relações gêneroespécie, todo-parte, propriedade-possuidor e ação-agente viabilizadas pelas ligações entre facetas e focos (arranjadas em ciclos e níveis) com base em coordenação e subordinação de classes em cadeias, e, a hospitabilidade proporcionada pelos cânones e demais medidas de aumento de flexibilidade, demonstram o empenho de Ranganathan no que se refere ao relacionamento de assuntos.

A tentativa de solucionar o problema da ordem de importância dos elementos formadores dos termos compostos, contemplando as dimensões estáticas e dinâmicas do conteúdo de um documento, é outra semelhança entre Kaiser e Ranganathan. Ao definir categorias de assuntos, Kaiser lança os princípios da facetagem. Suas categorias Concreto, Processo e Lugar apresentam ligação direta com as categorias fundamentais Personalidade, Energia e Espaço definidas por Ranganathan. Como afirma Fujita (1989), é possível encontrar a contribuição de Ranganathan para a formação de cabeçalhos de assuntos na obra Dictionary Catalogue Code, onde Ranganathan resgata a idéia inicial de Kaiser e sugere o uso das categorias PMEST.

\section{Conclusões}

Sem escapar da linearidade característica de uma reflexão teórico-histórica, é possível inferir que há uma linha conceitual no âmbito do tratamento temático da informação, iniciada por Cutter, continuada por Kaiser e dinamizada por Ranganathan, que solidificou um avanço teórico para a organização do conhecimento.

A relação entre os princípios aqui apresentados visou demonstrar mais que um resgate conceitual a fim de conectar teorias e métodos que normalmente são estudados separadamente, intencionou evidenciar que catalogação, indexação e classificação desenvolveram, e desenvolvem, conjuntamente um saber teórico que configura o arcabouço da organização do conhecimento. No escopo deste artigo, observou-se que as contribuições de Cutter para a catalogação, de Kaiser para a indexação e de Ranganathan para a classificação compuseram a evolução do tratamento temático que culminou na teoria da classificação facetada. Desse modo, a interlocução entre esses pensadores proporciona maior clareza quanto ao construto teórico deste universo investigativo, visto que, os saberes e fazeres da organização do conhecimento se desenvolvem indissociavelmente com o tratamento temático da informação.

\section{Notas}

(1) O presente trabalho fundamenta-se nas primeiras etapas da investigação doutoral "A abordagem facetada do Classification Research Group como aporte teórico às Ontologias de Fundamentação" (financiada pela Fundação de Amparo à Pesquisa do Estado de São Paulo FAPESP) desenvolvida na Universidade Estadual Paulista - UNESP, sob a orientação do Prof. Dr. José Augusto Chaves Guimarães. Nesse contexto, aborda-se princípios teóricos que antecederam os trabalhos do Classification Research Group, com o fim de compreender a articulação conceitual formadora do pensamento facetado no âmbito da Organização do Conhecimento.

(2) Entrada é o registro de um documento [livro] em um catálogo por meio do título, autor, assunto etc. Entrada de assunto é o "registro sob o nome selecionado para o catalogador indicar o assunto" (Cutter, 1904, p. 20, tradução livre).

(3) Referência às Cinco Leis da Biblioteconomia, publicadas primeiramente na obra "The Five Laws of Library Science, 1931.

\section{Referências}

Barbosa, A. P. (1969). Teoria e prática dos sistemas de classificação bibliográfica. Rio de Janeiro: Instituto Brasileiro de Bibliografia e Documentação, 1969. 441 p. (Obras Didáticas; 1).

Barité, M. (1998). Referenciales teóricos vigentes en el área de tratamiento temático de la información y su expresión metodológica. Porto Alegre: ABEBD, 1998. 7 p. [Relatório técnico do II Encontro de Dirigentes dos cursos superiores de Biblioteconomia dos países do Mercosul, Buenos Aires, nov. 1997].

Brascher, M.; Café, L. (2008). Organização da informação ou organização do conhecimento. // Enancib - Encontro Nacional de Pesquisa em Ciência da Informação, 9. Diversidade Cultural e Políticas de Informação, São Paulo, 2008. http://www.enancib2008.com.br/ (2008-10-10).

Cesarino, M. A. da N.; Pinto, M. C. M. F. (1978). Cabeçalho de assunto como linguagem de indexação. // Revista da Escola de Biblioteconomia, UFMG, Belo Horizonte. 7:2 (set. 1978) 268-88.

Chaumier, J. (1988). Indexação: conceito, etapas, instrumentos. Trad. José Augusto Chaves Guimarães. // Revista Brasileira de Biblioteconomia e Documentação, São Paulo. 21:1/2 (jan./jun. 1988) 63-79.

Coates, E. J. (1988). Subject catagues: headings and structure. London : The Library Association, 1988.

Cutter, C. A. Rules for a dictionary catalog. 4 ed. Washington: Government Printing Office, 1904. 173 p. (U.S. Bureau of Education. Special Report on Public Libreries; 2) 
Foskett, A.C. (1973). A abordagem temática da informação. Tradução de Antônio Agenor Briquet de Lemos. São Paulo: Polígono; Brasília: Ed.UnB, 1973.

Foskett, A.C. (1983). The subject approach to information. 5. ed. London: Clive Bingley, 1986.

Fujita, M. S. (1989). Precis na língua portuguesa: teoria e prática de indexação. Brasília: Editora da UNB, 1989.

Guimaraes, J. A. C. (2009). Abordagens teóricas de tratamento temático da informação (TTI): catalogação de assunto, indexação e análise documental. // García Marco, F. J. (org.) Avances y perspectivas en sistemas de información y documentación. Scire, Zaragoza, 2009, p. 105-117.

Guimaraes, J. A. C. (2008). A dimensão teórica do tratamento temático da informação e suas interlocuções com o universo científico da International Society for Knowledge Organization (ISKO). // Revista Ibero-Americana de Ciência da Informação 1 (2008) 77-99.

Hjørland, B. (2003). Fundamentals of knowledge organization. // Knowl. Org. 30:2 (2003) 87-111.

Iyer, H. (1995). Classificatory structures: concepts, relations and representation. INDEXSVerlag, 1995. (The Books for Knowledge Organization, 2).

Kaiser, L. O. (1911). Systematic indexing. London: Isaac Pitman \& Sons, 1911 (The Card Sistem Series, 2). http://www.archive.org/stream/systematicindexi00kaisuof t\#page/n0/mode/2up (2010-01-28).

Langridge, D. W. (1977). Classificação: abordagem para estudantes de biblioteconomia. Trad. Rosali P. Fernandez. Rio de Janeiro: Interciência, 1977.

Lima, G. A. B. (2004). O modelo simplificado para análise facetada de Spiteri a partir de Ranganathan e do Classification Research Group // Inf. Cult. Soc., Bueno Aires. 11, (jul./dic. 2004).

Maltby A. (1975). Sayers' Manual of classification for librarians. London: A. Deutsch / A Grafton Book, 1975.

Metcalfe, J. (1959). Subject classifying and indexing of libraries and literature. New York: Scarecrow, 1959.

Mey, E. S. A. (1987). Catalogação e descrição bibliográfica: contribuições a uma teoria. Brasília: Associação dos Bibliotecários do Distrito Federal, 1987.

Mills, J. (1960). A morden outline of library classification. London, Chapman and Hall, 1960.

Piedade, M. A. R. (1977). Introdução à teoria da classificação. Rio de Janeiro: Interciência, 1977.

Piedade, M. A. R. (1983). Introdução à teoria da classificação. 2. ed. Rio de Janeiro: Interciência, 1983.

Ranganathan, S. R. (1976). Colon classification. 6. ed., 4. reimpr. Bombay; Calcutta; New Delhi; Madras; Lucknow; Bangalore; London; New York: Asia Publishing House, 1976.

Rodriguez, R. D. (1984). Kaiser's systematic indexing. // Library resources \& technical services. (apr./jun, 1984) 163-173.

Straioto, A. C.; Guimarães, J. A. C. (2004). A abordagem facetada no contexto da organização do conhecimento: elementos históricos // Páginas a\&b (arquivos \& bibliotecas). Lisboa. 14 (2004) 109-136.

Recibido: 2010-04-13. Revisado: 2010-06-14. Aceptado: 2010-07-06. 
